\title{
Variations of Ground-level Ozone Concentration in Malaysia: A Case Study in West Coast of Peninsular Malaysia
}

\author{
Nur Izzah Mohamad Hashim ${ }^{1, *}$, Norazian Mohamed Noor ${ }^{1}$ \\ ${ }^{1}$ School of Environmental Engineering, University Malaysia Perlis (UniMAP), Kompleks Pusat \\ Pengajian Jejawi 3, 02600 Arau, Perlis, Malaysia.
}

\begin{abstract}
Hourly ground ozone concentration, measured from the monitoring stations in the West Coast of Peninsular Malaysia for the period of 10 years (2003-2012) were used to analyse the ozone characteristic in Nilai, Melaka and Petaling Jaya. The prediction of tropospheric ozone concentrations is very important due to the negative impacts of ozone on human health, climate and vegetation. The mean concentration of ozone at the studied areas had not exceeded the recommended value of Malaysia Ambient Air Quality Guideline (MAAQG) for 8-hour average $(0.06 \mathrm{ppm})$, however some of the measurements exceeded the hourly permitted concentration by MAAQG that is $0.1 \mathrm{ppm}$. Higher concentration of ozone can be observed during the daytime since ozone needs sunlight for the photochemical reactions. The diurnal cycle of ozone concentration has a mid-day peak (14:00-15:00) and lower night-time concentrations. The ozone concentration slowly rises after the sun rises (08:00), reaching a maximum during daytime and then decreases until the next morning.
\end{abstract}

\section{Introduction}

Ozone (O3) is a gas composed of three atoms of oxygen and occurs both in the Earth's upper atmosphere and at ground level [1]. It also can be beneficial "good ozone" or detrimental "bad ozone". In addition, ozone is also known as the greenhouse gas that has been the subject of the previous researches in the recent years [2,3]. Besides that, it regulates $\mathrm{OH}$ and $\mathrm{NO} 3$ radicals in the atmosphere during day and night-time respectively. It has been proved to be a serious air pollution problem for many countries all over the world [4] including Malaysia. In Malaysia, ground-level ozone was found to be one of the major pollutants since 2004 [5]. It is formed from chemical reactions among primary air pollutants, such as nitrogen oxides and volatile organic compounds in the presence of sunlight [6]. This air pollutant with high concentrations deserve the special attention due to capability of causing adverse health effect towards human health and on the environment [7] (WHO, 2003). O3 could irritate the respiratory system, reduce lung functions, and

\footnotetext{
${ }^{*}$ Corresponding author: nurizzah_hashim91@yahoo.com
} 
aggravate asthma problems and chronic lung diseases [8] (EPA, 2008). Active children, active adults, and people with respiratory diseases are people groups particularly sensitive to ozone [9].

Thus, it is necessary and quite urgent to gain a good understanding of the characteristics of ozone pollution in Malaysia and it can be used as fundamental tool for forecast [10], hence mandatory public warnings and traffic restrictions can be planned [11]. In this study, 10 years of hourly ozone (O3) monitoring records from three stations i.e. Nilai, Melaka and Petaling Jaya were selected to be analysed. These three locations were chosen because there are situated in the west coast of peninsular Malaysia that are more developed than the East Coast region, hence the air quality are expected to be more deteriorated.

\section{Material and methods}

In this research, the measured records of hourly $\mathrm{O} 3$ and meteorological from three stations in Malaysia were chosen. In this research, three sites are selected namely Klang in Selangor, Muar in Johor and Seremban in Negeri Sembilan. The hourly O3 concentrations records from 2003 to 2012 were used due to the high level of $\mathrm{O} 3$ concentration were released or emitted in atmosphere during that particular time. All the hourly O3 concentration and meteorological data were provided by DoE and were regularly subjected to quality control.

\subsection{Ozone Data Collection}

Ten years of ground level ozone concentration from 2003 to 2012 were obtained from air quality monitoring in Nilai, Melaka and Petaling Jaya. The data were owned by Department of Environment (DOE) Malaysia, however are managed by Alam Sekitar Malaysia Sdn. Bhd. The ozone concentration was measured using Teledyne O3 Analyser Model 400A UV Absorption. The analyser uses a system based on the Beer-Lambert law for measuruing low ranges of $\mathrm{O} 3$ in ambient air.

\subsection{Data Analysis}

The hourly and diurnal data of ground level ozone concentration were examined visually using box and whisker plot. For the descriptive statistics, two tests were conducted i.e. i) measures of central tendency (mean, median) and; ii) measures of dispersion (range, standard deviation).

\section{Results And Discussion}

Table 1 and summarizes the descriptive statistics of ozone concentration for day and nighttime in Nilai, Melaka and Petaling Jaya for day and night in Nilai, Melaka and Petaling Jaya respectively. The mean values for all areas during daytime and night-time were higher than the median. This indicated that the data are skewed to the right and that extreme events occurred. The mean concentration of ozone is recorded low than the recommended value of Malaysia Ambient Air Quality Guideline (MAAQG) that is $0.06 \mathrm{ppm}$. However, the maximum values recorded for all stations during daytime exceeded the stipulated value of MAAQG (0.06 ppm).

Figure 1 and Figure 2 shows the boxplot of ozone concentration for daytime and nighttime at the studied areas. Obviously, the day concentration of ground-level ozone is much 
higher compared to the night concentration. From Figure 1, for most of the years, Melaka gives the higher readings compared to Nilai and Petaling Jaya. However, the mean concentrations of ozone do not exceeded the recommended value of Malaysia Ambient Air Quality Guideline (MAAQG) that is $0.06 \mathrm{ppm}$. Though, it can be seen that for some of the years the ground-level concentration exceed the recommended value and this show that an extreme events occurred. The concentration of ground-level ozone during night- time (Figure 2) is far below the daytime concentration. Ozone need sunlight to undergo chemical reactions to be formed, hence, the concentration of $\mathrm{O} 3$ is higher during daytime. From Figure 2, Melaka recorded the highest concentration of $\mathrm{O} 3$ compared to Nilai and Petaling Jaya. Furthermore, Petaling Jaya shows that $\mathrm{O} 3$ concentration was more convergence and less variable compared to others. All the values are far below the MAAQG except for only 1 reading in Melaka (2009).

Table 1. Statistics of $\mathrm{O}_{3}(\mathrm{ppm})$ in the Study Area for Daytime and Night-time

\begin{tabular}{|l|l|c|c|c|}
\hline & & Nilai & Melaka & $\begin{array}{c}\text { Petaling } \\
\text { Jaya }\end{array}$ \\
\hline \multirow{4}{*}{ Daytime } & Mean & 0.0253 & 0.0277 & 0.0236 \\
\cline { 2 - 5 } & Median & 0.0244 & 0.0269 & 0.0223 \\
\cline { 2 - 5 } & S.D & 0.0092 & 0.0085 & 0.0097 \\
\cline { 2 - 5 } & Min & 0.0021 & 0.0030 & 0.0008 \\
\cline { 2 - 5 } & Max & 0.0665 & 0.0715 & 0.0657 \\
\hline \multirow{5}{*}{ Night-time } & Mean & 0.0074 & 0.0119 & 0.0039 \\
\cline { 2 - 5 } & Median & 0.0055 & 0.0112 & 0.0027 \\
\cline { 2 - 5 } & S.D & 0.0063 & 0.0067 & 0.0038 \\
\cline { 2 - 5 } & Min & 0.0000 & 0.0000 & 0.0000 \\
\cline { 2 - 5 } & Max & 0.0465 & 0.0690 & 0.0455 \\
\hline
\end{tabular}

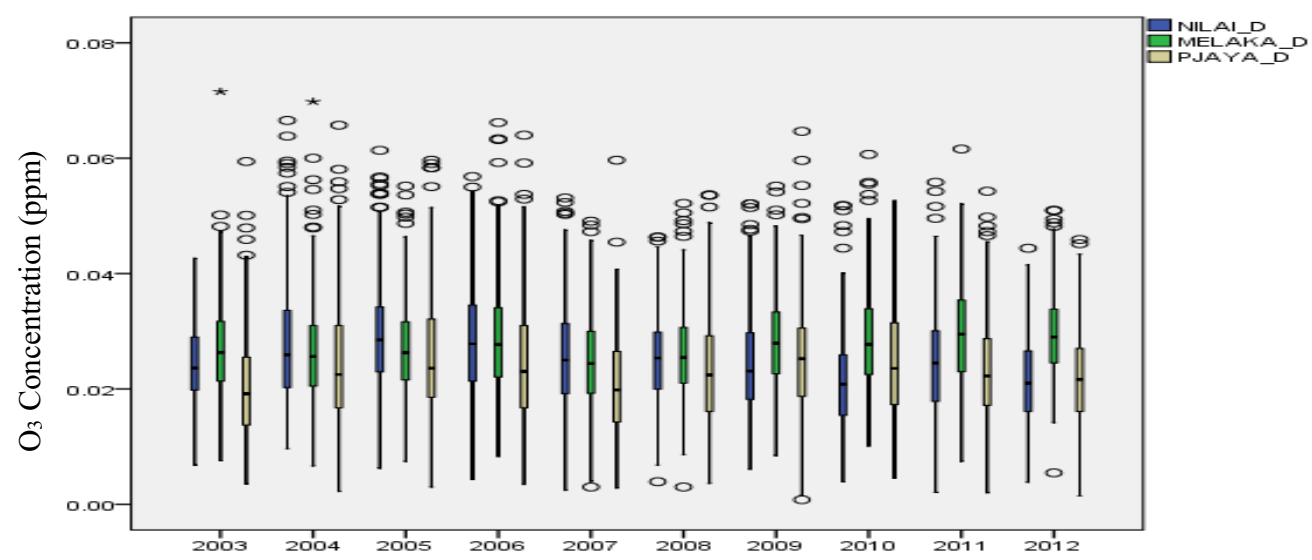

Fig. 1. Box plot (Day Record) for Nilai, Melaka and Petaling Jaya 


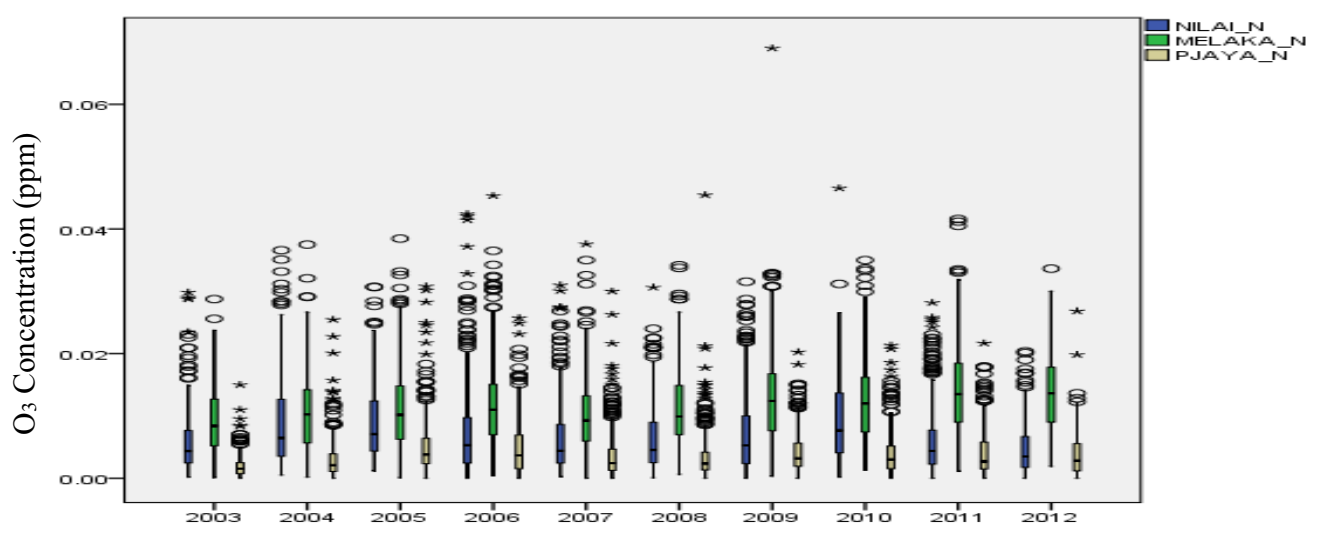

Fig. 2. Box plot (Night Record) for Nilai, Melaka and Petaling Jaya

The diurnal variations of $\mathrm{O} 3$ concentrations during the study period are graphically illustrated in Figure 3. The $\mathrm{O} 3$ diurnal variation of each site exhibited a similar pattern, but the magnitudes of the variations differed. The diurnal pattern of $\mathrm{O} 3$ for each site is characterized by a maximum concentration in the afternoon and a minimum during nightime. This variation between day and night generally coincides with the amount of higher solar radiation intensity during the day, which is the favourable condition for powering photochemical reactions. In addition, the diurnal cycle of ozone are shaped like double waves. The diurnal cycle of ozone concentration reaches a peak during the middle of the day, while during the night-time, there was a lower ozone concentration [1]. Latif et al. (2012) stated that this is because the reaction of photochemical of $\mathrm{O} 3$ concentration such as VOC with NOx that were originated from transportation [12]. Ismail et al., (2016) proved that during the daytime, the ozone concentration slowly increases after the sun rises until it reached its maximum [13]. While, it slowly decreases until the next morning. The graphs above show that the increasing ozone concentration occurred from 08:00 to 13:00-14:00 due to the solar radiation [14]. From the boxplot, Nilai shows higher variations of diurnal ozone concentration compared to others. However, the highest peak of ozone concentration was recorded in Petaling Jaya at hour 13:00-14:00. 

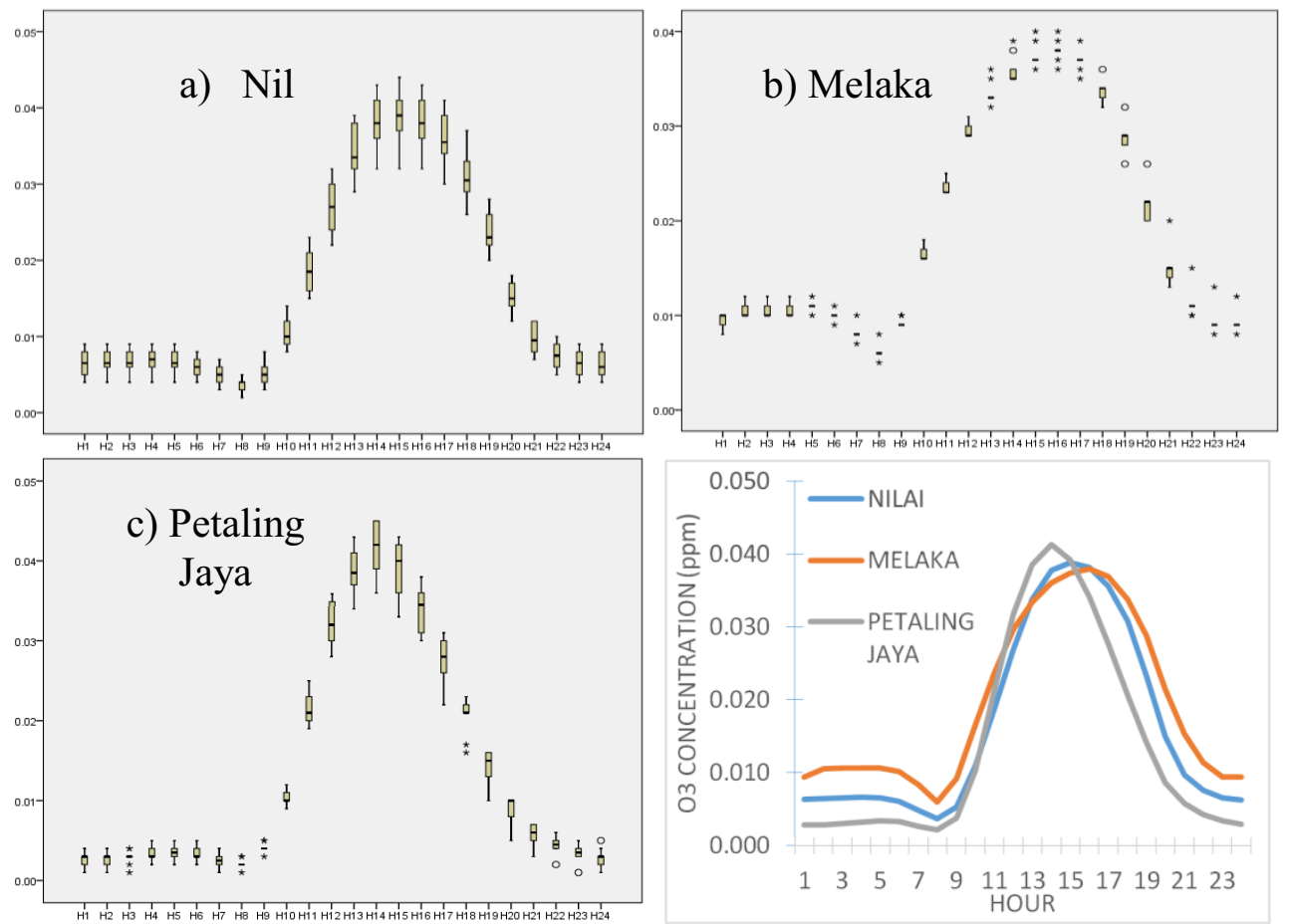

Fig. 3. Diurnal variations of $\mathrm{O}_{3}$ concentrations

\section{Conclusion}

This study analyses the concentrations of $\mathrm{O} 3$ in the three areas in the West Coast of Peninsular Malaysia from 2003 to 2012. The descriptive statistics and the diurnal variations of the hourly $\mathrm{O} 3$ concentration in Nilai, Petaling Jaya and Melaka were observed and investigated. Higher concentration of ground level ozone during daytime was observed at all study areas due to higher solar radiation intensity during that time. Most of the time, Melaka recorded higher $\mathrm{O} 3$ concentration compared to other areas. However, the mean concentration of $\mathrm{O} 3$ in these three sites does not exceed the recommended value of MAAQG for 8-hour average that is $0.06 \mathrm{ppm}$. The diurnal variation of $\mathrm{O} 3$ concentration exhibited a mid-day peak at 14:00-15:00 and had lower night-time concentrations. The O3 concentration slowly rises after the sun rises (08:00), reaching a maximum during daytime and then decreases until the next morning. This pattern was majorly influenced by the activity of photochemical reactions of $\mathrm{O} 3$ during the daytime.

\section{References}

1. N.A. Ramli, N.D. Ghazali, A.S Yahaya, Malaysian Journal of Environmental Management 11, 57 (2010)

2. M. Musa, A.A. Jemain, W.A.N. Zawiah, W.A.N Zin, Journal of Quality Measurement and Analysis, 9, 9 (2013)

3. M.A. Barrero, J.O. Grimalt, L. Canton, Chemometr. Intell. Lab., 80, 67 (2006)

4. C.M. Atkinson Palombo, J.A. Miller, J.R.C. Balling, Atmos. Environ. 40, 7644 (2006) 
5. Department of Environment (DOE) Malaysia (2012). Malaysia Environmental Quality Report 2012. Kuala Lumpur: department of Environment, Ministry of Sciences, Technology and Environment, Malaysia.

6. C. Duenas, M.C. Fernandez, S.J. Canete, Carretero, E. Liger, Chemosphere 61, 1379 (2005)

7. Environmental Protection Agency. (2008). Ozone Pollution. Retrieved: 2nd August 2016. http://www.epa.gov/air/ozonepollution/pdfs/health.pdf

8. World Health Organization, Health aspects of air pollution with particulate matter, ozone and nitrogen dioxide. (Bonn, Germany, 2003)

9. E. Agirre, L.J.R Barron, Forecasting Model, 208-218 (2010)

10. S.I.V Sousa, F.G. Martins, M.C. Pereira, M.C.M. Alvim Ferraz, Chemosphere 64, 1141 (2006)

11. S. Bordignon, C. Gaetan, F. Lisi, Stat. Methods. Appt., 11, 227 (2002)

12. M.T. Latif, L.S. Huey, L. Juneng, Atmos. Environ., 61, 434 (2012)

13. M. Ismail, S. Abdullah, F.S. Yuen, N.A. Ghazali, Environment Asia, 9, 1 (2016)

14. A.G. Ulke, N.A.Mazzeo, Atmos. Environ., 32, 1615 (1998) 